\title{
TRANS al cabo de veinticinco años
}

Consejo de Redacción
En 1996 estaba ya establecida la titulación en Traducción e Interpretación en la Universidad de Málaga, y la nueva área académica de dicha especialidad eclosionaba y requería órganos adecuados para su avance y difusión. Con esa finalidad se creó TRANS: Revista de Traductología, no sin antes tener que vencer ciertas resistencias, quizá esperables ya que se trataba de un área y titulación nuevas. De inestimable ayuda fue entonces el Profesor Pedro Rodríguez Oliva, a la sazón Vicerrector de Cultura en nuestra Universidad, sin cuyo apoyo la revista puede que no hubiese llegado a ver la luz.

Para conmemorar este aniversario, TRANS publica un dosier sobre la traducción y la interpretación en la España del siglo XVI, centuria determinante para la historia cultural española en tantos aspectos, incluidos los que nos conciernen. La sección monográfica, coordinada por Luis Bernabé Pons y José Francisco Ruiz Casanova, la componen trabajos de los dos investigadores mencionados (sobre la traducción del árabe y sobre las versiones de los clásicos, respectivamente), así como las de otros especialistas: Juan Gabriel López Guix (las versiones de la Biblia), Anna Gargatagli (la interpretación y la traducción en América), José Antonio Sabio (la traducción entre las lenguas peninsulares), Antonio Bueno García (la participación de los religiosos en la empresa traductora) y Claire Gilbert (el papel de la traducción del árabe en la política de los Austrias). Les quedamos muy agradecidos. 